\title{
EFEKTIVITAS BENTUK ATRAKTOR CUMI-CUMI SEBAGAI MEDIA PENEMPELAN TELUR CUMI-CUMI (Loligo sp)
}

\author{
EFFECTIVENESS OF FORM ATTRACTOR SQUID AS MEDIA ATTACHMENT SQUID \\ EGG (Loligo sp)
}

\author{
Mulyono S. Baskoro ${ }^{1)}$, M. Fedi A. Sondita ${ }^{1)}$, Roza Yusfiandayani ${ }^{1)}$ \\ dan Indra Ambalika Syari2) \\ ${ }^{1)}$ Staf pengajar Fakultas Perikanan dan Ilmu Kelautan - Institut Pertanian Bogor \\ ${ }^{2}$ Staf Pengajar Ilmu Kelautan Universitas Bangka Belitung (UBB) \\ baskoro.mul@gmail.com
}

Diterima tanggal : 5 Januari 2015, diterima setelah perbaikan : 12 Januari 2017, disetujui tanggal: 16 Januari 2017

\begin{abstract}
ABSTRAK
Produksi cumi-cumi (Loligo sp) masih sangat tergantung dari hasil tangkapan, sehingga jumlahnya sangat bergantung dengan kondisi alam. Jumlah hasil tangkapan cumi-cumi (Loligo sp) yang terus ditingkatkan namun tidak diiringi dengan kegiatan pengayaan stoknya, maka untuk mempertahankan populasi cumi-cumi diperlukan teknologi terapan yang dapat membantu cumi-cumi (Loligo sp) mudah berkembang biak. Atraktor cumi-cumi merupakan salah satu teknologi yang dapat diaplikasikan untuk membantu pengayaan stok cumi-cumi (Loligo sp) di alam. Atraktor ini dapat dibuat dari berbagai jenis bahan dan berbagai bentuk, tergantung dari mudah didapatnya bahan untuk pembuatan atraktor. Penelitian atraktor cumi-cumi (Loligo sp) yang berbeda bentuk dan bahan dilakukan di Perairan Tuing, Kabupaten Bangka, Provinsi Kepulauan Bangka Belitung pada bulan Oktober 2012 sampai bulan Juni 2013. Enam buah atraktor berbentuk kotak dari bahan kayu dan enam buah atraktor berbentuk silinder dari drum bekas diteliti untuk mengetahui keefektifan dari dua bentuk atraktor. Atraktor dipasang pada kedalaman 3-5m dengan cara berselingan antara bentuk kotak dan silinder. Hasil penelitian menunjukkan bahwa penempelan telur cumi-cumi (Loligo sp) lebih banyak pada atraktor bentuk silinder yang mencapai 95\% dibandingkan dengan bentuk kotak yang hanya 5\%. Atraktor cumi-cumi bentuk silinder dari drum bekas lebih efektif karena bentuknya yang seperti gowa yang dapat menarik atau merangsang cumi-cumi (Loligo sp) untuk menempelkan telurnya.
\end{abstract}

Kata kunci : cumi-cumi, atraktor, bentuk atraktor

\section{ABSTRACT}

Production of squid (Loligo sp) still largely on the catch, so the catch relies very much on natural conditions. Total catches of squid (Loligo sp) are constantly being upgraded, but not accompanied by the stock enrichment. Therefore, to sustain the populations of squid (Loligo sp) applied technologies are required to facilitate the squid (Loligo sp) to breed. The squid atractor is one of the technologies that can be introduced to assist of the stock enrichment of the squid (Loligo sp) in the wild. This attractor can be made from various types of materials and forms, depending on the ease of getting material for attractor manufacture.The research of squid attractor used different forms and materials, and the attractors were tested in Tuing waters, Bangka, Bangka Belitung Province during the period of October 2012 until June 2013. Six box attractor of wood and six cylindrical attractor of drums were investigated to reveal the effectiveness of two forms of attractors. The squid attractors were deployed at 3-5m depth alternately between box and cylindrical attractors. The results showed that the attachment of the squid eggs was found more on cylindrical form attractor reaching $95 \%$ compared with a box form attractor being only 5\%. The cylindrical squid attractor made from used drums was more effective because the form was like a cave attracting or stimulating the squid to attach their eggs.

Keywords : Attractor, Form attractor, Squid (Loligo sp),

Efektivitas Bentuk Atraktor Cumi-Cumi Sebagai Media Penempelan Telur Cumi-Cumi (Loligo Sp) - Mulyono S. Baskoro, M. Fedi A. Sondita, Roza Yusfiandayani dan Indra Ambalika Syari 


\section{PENDAHULUAN}

Indonesia merupakan negara pengekspor cumi-cumi dengan nilai tertinggi kedua untuk komoditas non ikan setelah udang. Harga cumi-cumi (Loligo sp) di pasaran cukup tinggi dan stabil. Saat musim cumi-cumi (Loligo sp) melimpah, komoditas ini dapat diolah menjadi produk olahan seperti cumi kering, cumi asin, kerupuk cumi dan makanan olahan lainnya dengan harga jual yang lebih tinggi dan masa konsumsi yang lebih lama. Saat ini cumi-cumi (Loligo sp) belum dibudidayakan sehingga produksinya masih sangat bergantung pada hasil tangkapan di alam. Cumi Bangka (Loligo chinensis. Gray, 1849) merupakan jenis cumi yang bernilai ekonomis tinggi dan merupakan komoditas ekspor. Jenis cumi-cumi ini sudah semakin sulit didapat di perairan Indonesia secara umum, hal ini menggambarkan bahwa semakin berkurangnya stok cumi-cumi (Loligo sp) di alam.

Intensitas penangkapan yang semakin tinggi dengan bertambahnya jumlah armada dan modernisasi alat tangkap dapat menyebabkan penangkapan yang berlebih atau over fishing. Selain itu, tingginya laju degradasi habitat pemijahan dan pembesaran cumi-cumi di daerah pesisir akibat pencemaran, penangkapan yang tidak ramah lingkungan, sedimentasi, dan konversi lahan sebagai desakan pembangunan dapat mengakibatkan berkurangnya populasi cumi-cumi (Loligo sp). Oleh karena itu, diperlukan upaya pemulihan stok cumi-cumi (Loligo sp) yang dapat dilakukan secara alamiah dengan memanfaatkan teknologi atraktor. Atraktor cumi-cumi merupakan salah satu teknologi tepat guna untuk pengembangan program pengayaan stok cumi-cumi (Loligo sp) di masa yang akan datang (Baskoro et al, 2011). Bentuk dan bahan pembuat atraktor cumi-cumi sampai saat ini belum aplikatif dengan kondisi lingkungan perairan dan kondisi nelayan yang berada di daerah-daerah terpencil. Sehingga dipandang perlu dirancang rekayasa bentuk atraktor cumi-cumi yang sederhana, mudah dibuat dan menggunakan bahan-bahan yang relatif murah dan mudah didapat di daerah.

Penelitian efektivitas atraktor cumi-cumi sebagai media penempelan telur cumi-cumi (Loligo sp) dengan mengkaji bentuk dan bahan serta kedalaman pemasangannya penting dilakukan agar teknologi tepat guna ini dapat diaplikasikan sesuai dengan kondisi lingkungan. Hasil penelitian diharapkan dapat membantu dalam aktivitas pengayaan sumberdaya cumi-cumi (Loligo sp).

\section{BAHAN DAN METODE}

\section{Waktu dan Lokasi Penelitian}

Penelitian dilakukan di Perairan Tuing Kecamatan Riau Silip, Kabupaten Bangka, Provinsi Kepulauan Bangka Belitung selama sembilan bulan yaitu mulai dari bulan Oktober 2012 sampai dengan bulan Juni 2013. Secara geografis, lokasi penelitian terletak pada $01^{\circ}$ 35,4' LS dan $106^{\circ} 01,8^{\prime}$ BT (Gambar 1). Kegiatan penelitian lapangan terdiri dari tiga tahapan, yaitu; (1) pembuatan atraktor cumicumi, (2) pemasangan atraktor cumi-cumi, dan (3) pengamatan dan analisis data. 


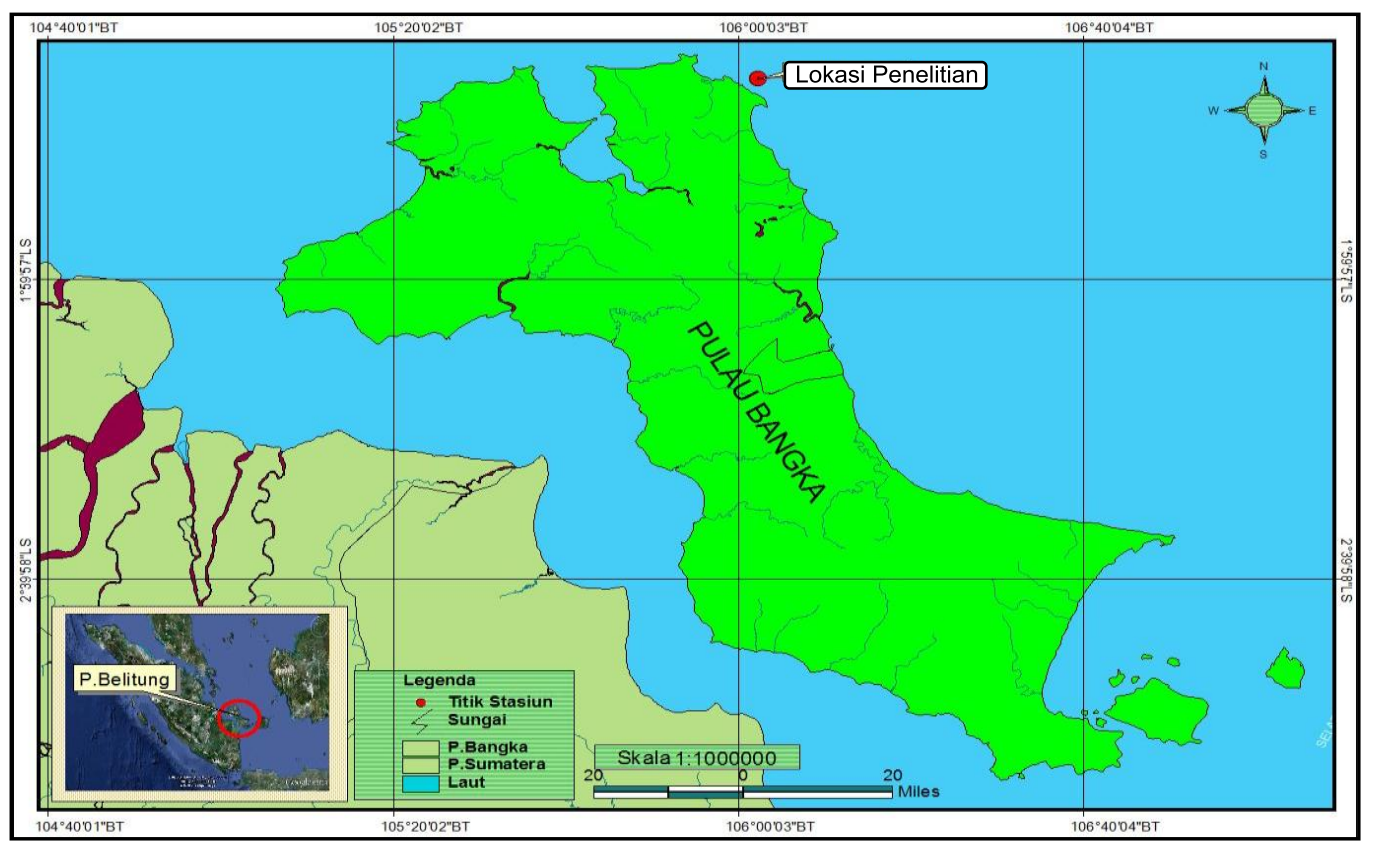

Gambar 1. Lokasi Penelitian (Perairan Tuing Kecamatan Riau Silip, Kabupaten Bangka, Provinsi Kepulauan Bangka Belitung)

\section{Bentuk dan Bahan Atraktor}

Bentuk dan bahan utama atraktor cumi-cumi dalam penelitian ini adalah atraktor cumi-cumi berbentuk kotak dengan ukuran 75 × 50 × 35 $\mathrm{cm}^{3}$ dengan kerangka dari kayu dan atraktor cumi-cumi berbentuk tabung (silindris) dari drum besi bekas dengan ukuran diameter 50 $\mathrm{cm}$ dan tinggi $90 \mathrm{~cm}$. Atraktor cumi-cumi yang berbentuk kotak, selain dilengkapi dengan talitali rami yang berdiri vertikal pada bagian tengahnya, bagian rangkanya pada sisi bagian atas ditutupi waring yang bertujuan untuk membuat kondisi dalam atraktor teduh atau agak gelap (Gambar 2). Atraktor cumi-cumi yang berbentuk silinder (silindris) dibuat dari drum bekas dan dilengkapi dengan tali-tali rami yang berdiri vertikal pada bagian tengahnya (Gambar 3). Masing-masing atraktor cumi dipasang sebanyak 6 buah pemikat dari bahan tali rami (bahan organik) agar cumi-cumi tertarik menempelkan telurnya pada pemikat di dalam atraktor cumi-cumi yang telah ditenggelamkan atau dipasang pada kedalaman tertentu.

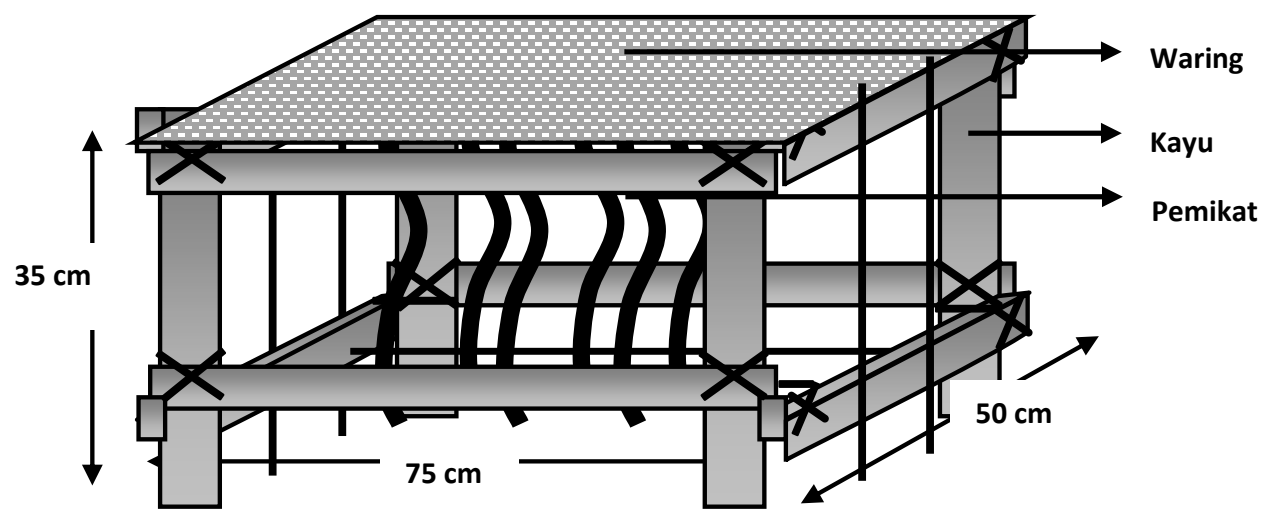

Gambar 2. Atraktor Cumi-cumi Berbentuk Kotak

Efektivitas Bentuk Atraktor Cumi-Cumi Sebagai Media Penempelan Telur Cumi-Cumi (Loligo Sp) - Mulyono S. Baskoro, M. Fedi A. Sondita, Roza Yusfiandayani dan Indra Ambalika Syari 


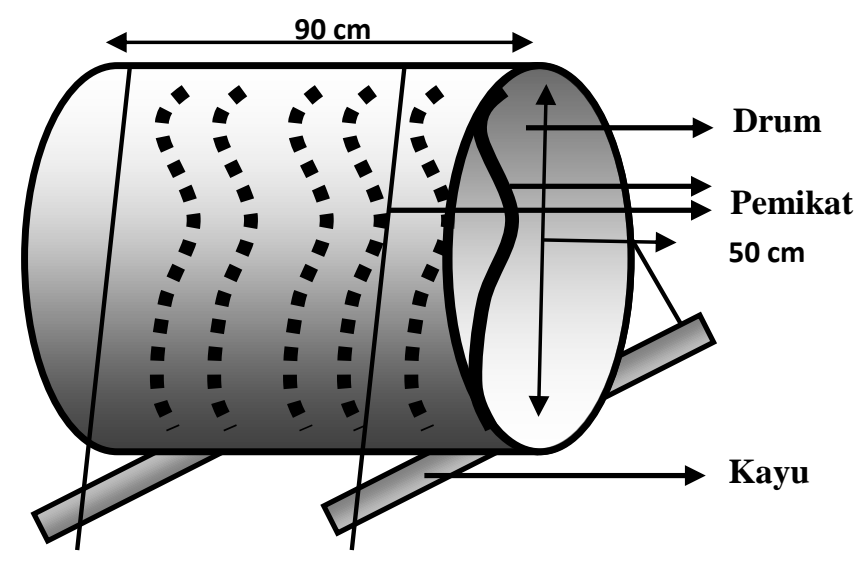

Gambar 3. Atraktor Cumi-cumi Berbentuk Silindris Drum Besi Bekas ukuran diameter $50 \mathrm{~cm}$ dan tinggi $90 \mathrm{~cm}$

\section{Pemasangan Atraktor Cumi-cumi}

Atraktor cumi-cumi ditenggelamkan pada kedalaman 3-5m pada saat kondisi surut yang terdiri atas 6 unit atraktor berbentuk kotak dan 6 unit atraktor berbentuk silinder, sehingga total atraktor cumi-cumi berjumlah 12 unit. Atraktor disusun secara berselingan antara yang berbentuk kotak dengan yang berbentuk silinder dengan jarak antar atraktor adalah 5m, dipasang pada dasar perairan dengan substrat pasir (Gambar 4 dan 5). Pengamatan mulai dilakukan setelah atraktor dipasang pada perairan, yaitu masing-masing pada bulan November dan Desember 2012, bulan April

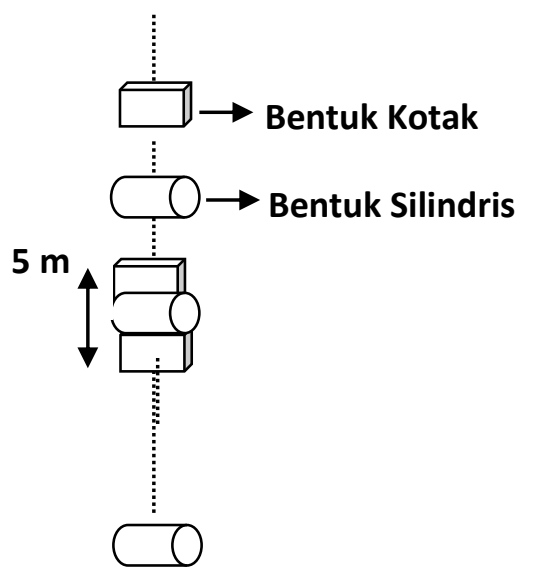

dan Mei 2013. Selanjutnya dilakukan analisis dari jumlah telur cumi-cumi yang menempel pada setiap unit atraktor dengan menyelam dibantu dengan alat SCUBA dan menghitung jumlah telur secara manual. Identifikasi jenis cumi-cumi (Loligo sp) yang ada di lokasi penelitian dilalukan dengan menggunakan buku "Cephalopods a World Guide" (Norman, 2003; Roper et al, 1984), dan juga dengan analisis sampel preparat basah cumi-cumi langsung di Museum Zoologi, Lembaga Ilmu Pengetahuan Indonesia (LIPI) CibinongBogor.

Gambar 4. Disain Rangkaian Atraktor Cumi-cumi Tampak Atas dalam Penelitian 

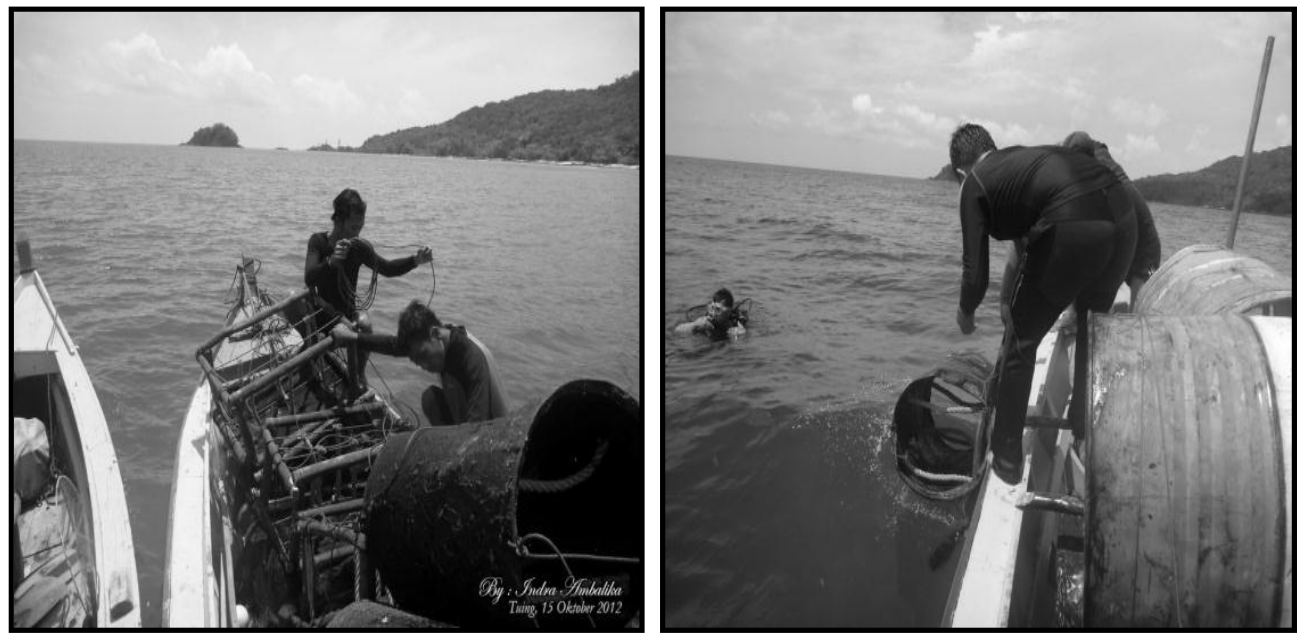

Gambar 5. Pemasangan Atraktor Cumi-cumi di Lokasi Penelitian

\section{Efektivitas Atraktor Cumi-cumi}

Efektivitas atraktor cumi-cumi dianalisis dengan menghitung tingkat keberhasilan atraktor dalam mengumpulkan telur cumi- cumi. Indikator tingkat keefektifan adalah dengan menghitung prosentase jumlah atraktor yang ditempeli telur cumi-cumi (EA) yang dihitung menurut Baskoro dan Mustaruddin (2006) seperti berikut :

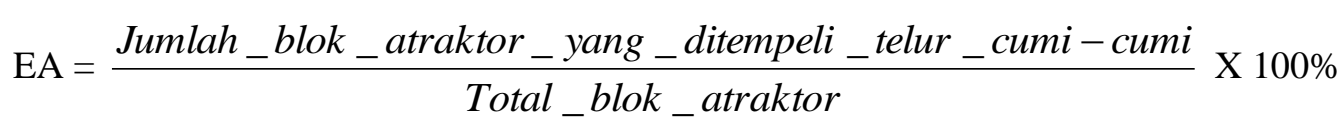

dimana : $\quad \mathrm{EA}=$ Efektivitas Atraktor (dalam persentase)

$$
\begin{array}{ll}
\mathrm{EA} \geq 60 \% & =\text { sangat efektif } \\
30 \%<\mathrm{EA}<60 \% & =\text { efektif } \\
\mathrm{EA} \leq 30 \% & =\text { kurang efektif }
\end{array}
$$

\section{HASIL DAN PEMBAHASAN}

Atraktor cumi-cumi yang dipasang pada lokasi penelitian hampir semuanya ditempeli oleh telur cumi-cumi dari jenis Cumi-cumi Bangka (Loligo chinensis Gray, 1849). Jenis cumicumi ini menjadi tujuan utama penangkapan bagi nelayan-nelayan karena harganya yang tinggi, misalnya banyak diburu oleh nelayan Thailand, Hongkong dan China (Norman, 2003). Secara morfologi Loligo chinensis hampir serupa dengan Loligo edulis (Sin et al., 2009). Kedua jenis cumi inipun secara geografi memiliki penyebaran yang sama (Roper et al., 1984). Salah satu cara yang digunakan untuk membedakan kedua spesies ini adalah dengan melihat gigi pada cincin perekat di tentakel kedua cumi-cumi tersebut, dimana pada Loligo chinensis memiliki 10-18 gigi berbentuk kerucut sedangkan pada Loligo edulis memiliki 6-12, seringnya 6-8 gigi berbentuk lebih tumpul (Vecchione et al., 1998). Cumi-cumi Bangka tersebar di perairan bagian Barat Samudera Pasifik, Laut Cina Selatan dan Timur hingga ke perairan Jepang, Laut Arafura, bagian Timur laut perairan Australia hingga perairan New South Wales (Roper et al., 1984).

Atraktor cumi-cumi berbentuk silinder dari drum bekas lebih banyak ditempeli telur cumicumi dibandingkan dengan atraktor cumi-cumi berbentuk kotak dari kayu. Selama pengamatan dalam penelitian jumlah kapsul

Efektivitas Bentuk Atraktor Cumi-Cumi Sebagai Media Penempelan Telur Cumi-Cumi (Loligo Sp) - Mulyono S. Baskoro, M. Fedi A. Sondita, Roza Yusfiandayani dan Indra Ambalika Syari 
telur cumi-cumi (Loligo chinensis Gray, 1849) yang menempel atau yang terdapat pada atraktor berbentuk silinder mencapai 3.028 kapsul telur atau 95\% dari total kapsul telur, sedangkan pada atraktor cumi-cumi berbentuk kotak hanya terdapat 141 kapsul telur atau 5\% dari total kapsul telur (Gambar 6 dan 7). Perbedaan jumlah ini diprediksi karena kondisi atraktor cumi-cumi yang berbentuk kotak lebih terbuka dibandingkan atraktor cumi-cumi yang berbentuk silinder. Atraktor cumi-cumi berbentuk kotak hanya tertutup pada bagian atasnya saja, kondisi ini masih membuat lingkungan di dalam atraktor kurang gelap atau masih agak terang, dimana cumi-cumi
(Loligo chinensis Gray, 1849) kurang menyukai kondisi lingkungan yang agak terang. Selain itu juga atraktor cumi-cumi berbentuk kotak yang bagian sisi kanan, kiri, depan dan belakangnya terbuka masih sangat dipengaruhi oleh arus, hal ini juga yang mempengaruhi kenyamanan cumi-cumi dalam menempelkan telur-telurnya. Berbeda dengan atraktor cumi-cumi berbentuk silinder yang lebih gelap seperti gowa, karena semua sisinya (kecuali bagian depan dan belakang drum) tertutup. Kondisi ini juga membuat atraktor berbentuk silinder lebih terlindung dari arus, sehingga dapat membuat nyaman bagi cumicumi untuk menempelkan telur-telurnya.

\section{Persentase Penempelan Telur}

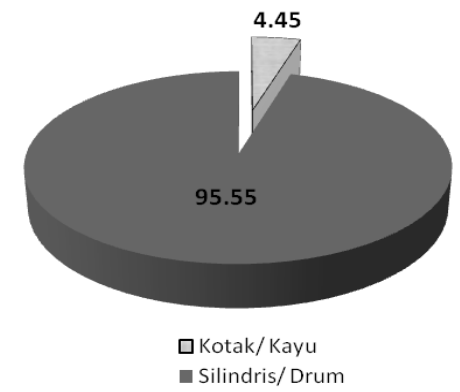

Gambar 6. Perbandingan Jumlah Kapsul Telur Cumi-cumi (Loligo chinensis Gray, 1849) menurut Bentuk Atraktor dalam Persentase
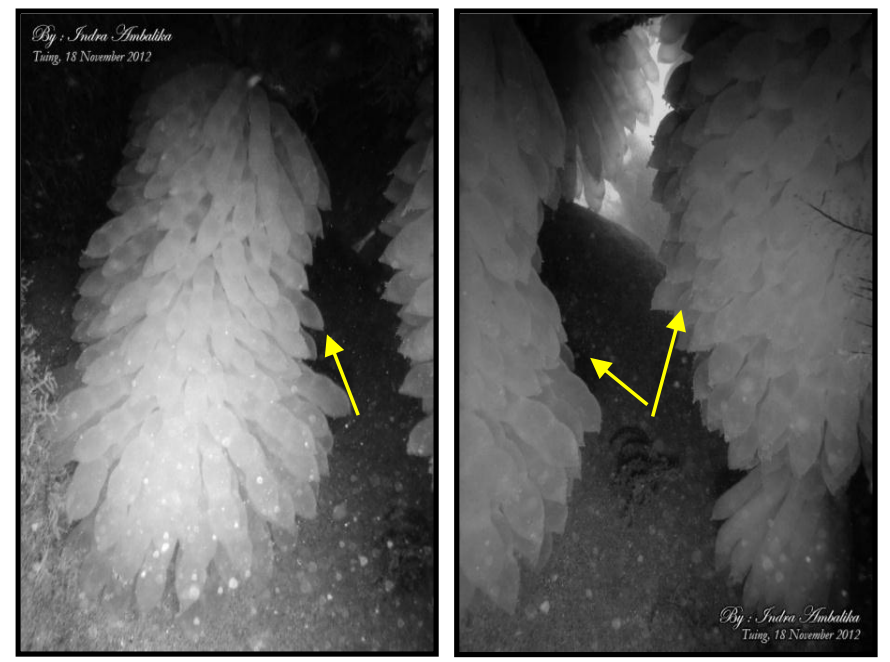

Gambar 7. Contoh Telur Cumi-cumi yang Menempel pada Atraktor

JURNAL KELAUTAN NASIONAL, Vol. 10, No. 3, Desember 2015, Hal. 177-184 
Analisis indeks efektivitas atraktor cumi-cumi dihitung dari jumlah atraktor yang ditempeli telur cumi-cumi untuk masing-masing bentuk atraktor. Atraktor cumi-cumi yang berbentuk silinder dari drum bekas lebih efektif menjadi tempat cumi-cumi menempelkan telur-telurnya dibandingkan dengan atraktor cumi-cumi yang berbentuk kotak dari kayu. Dari jumlah masing-masing 6 unit bentuk atraktor cumicumi yang dipasang, sebanyak 5 unit atraktor berbentuk silinder terdapat telur cumi-cumi (Loligo chinensis Gray, 1849) atau sebanyak $83,3 \%$. Sedangkan bentuk atraktor kotak sebanyak 2 unit ditempeli telur cumi-cumi (Loligo chinensis Gray, 1849) dari 6 unit yang

\section{KESIMPULAN DAN SARAN}

\section{Kesimpulan}

Bentuk atraktor cumi-cumi yang efektif untuk merangsang cumi-cumi (Loligo chinensis Gray, 1849) menempelkan telurnya adalah yang berbentuk silinder dari drum bekas. Bentuk silinder ini dapat ditempeli telur cumicumi (Loligo chinensis Gray, 1849) mencapai 3.028 kapsul telur atau 95\%, sedangkan pada atraktor cumi-cumi berbentuk kotak hanya terdapat 141 kapsul telur atau 5\% dari total kapsul telur. Tingkat efektivitas yang baik juga ditunjukkan oleh atraktor cumi-cumi berbentuk silinder, sebanyak $83,3 \%$ dari bentuk atraktor ini ditempeli telur cumi-cumi (Loligo chinensis Gray, 1849), sedangkan bentuk atraktor kotak hanya 33,3\% yang

\section{DAFTAR PUSTAKA}

Baskoro MS, F. Purwangka dan A. Suherman. (2011). Atraktor Cumi-cumi. Badan Penerbit Universitas Diponegoro. Semarang. 128 pp.

Baskoro MS dan Mustaruddin. (2006). Atraktor Cumi-cumi: Teknologi Potensial dan Tepat Guna untuk Pengembangan Kawasan Pantai Terpadu. Prosiding Seminar Nasional Perikanan Tangkap, Dep. PSP FPIK IPB. Bogor. dipasang atau sebanyak 33,3\%. Atraktor cumicumi berbentuk silinder dari drum bekas lebih disukai oleh cumi-cumi untuk menempelkan telurnya dibandingkan dengan rumpon cumicumi berbentuk kotak dari kayu yang ditutup dengan waring pada bagian atasnya. Bentuk silinder diduga lebih tertutup, sehingga telurtelur yang ditempelkan akan lebih terlindung dari arus, cahaya dan predator. Selain itu membuat cumi - cumi (Loligo chinensis Gray, 1849) lebih nyaman untuk menempelkan telurnya pada bentuk atraktor ini karena kondisi dalam atraktor yang agak gelap.

ditempeli telur cumi-cumi (Loligo chinensis Gray, 1849).

\section{Saran}

Penelitian perlu dilanjutkan dengan mendisain bahan-bahan atraktor cumi-cumi yang lebih efektif, efisien dan mudah didapat. Perlu juga dianalisis perkembangan telur cumi-cumi pada skala laboratorium untuk memprediksi tingkat keberhasilan hidup dari larva cumi-cumi.

\section{UCAPAN TERIMA KASIH}

Penulis menyampaikan terima kasih yang sedalam-dalamnya kepada nelayan Desa Tuing, Kecamatan Riau Silip, Kabupaten Bangka, Provinsi Kepulauan Bangka Belitung yang telah aktif membantu selama penelitian ini berlangsung.

Norman MD. (2003). Cephalopods a World Guide. CSIRO Publishing and the Gould League of Victoria Melbourne 96 pp.

Roper CFE. M.J. Sweeney and C.E Nauen. (1984). FAO species catalogue. Cephalopods of the world. An annotated and illustrated catalogue of species of interest to fisheries. FAO Fish Synop. 3 (125), 1-277.

Sin YW, C. Yau and K.H Chu. (2009). Morphological and genetic differentiation of two loliginid squids, Uroteuthis (Photololigo) chinensis and

Efektivitas Bentuk Atraktor Cumi-Cumi Sebagai Media Penempelan Telur Cumi-Cumi (Loligo Sp) - Mulyono S. Baskoro, M. Fedi A. Sondita, Roza Yusfiandayani dan Indra Ambalika Syari 
Uroteuthis (Photololigo) edulis

(Cephalopoda: Loligonidae). In Asia.

Elsevier Scientific Publishing Company,

Amsterdam: Fisheries Research (369)

$22-30$.
Vecchione, M., T.F. Brakoniecki, Y. Natsukari, and R.T Hanlon. (1998). A provisional generic classification of the family Loliginidae. Elsevier Scientific Publishing Company, Amsterdam: Fisheries Research (586) 215-222. 